\title{
FABRICACION DE PELLETS DE CARBONILLA, USANDO ASERRIN DE Pinus radiata (D. Don), COMO MATERIAL AGLOMERANTE
}

\author{
MANUFACTURING PELLETS OF CHARCOAL, USING SAWDUST OF \\ Pinus radiata (D. Don), AS A BINDER MATERIAL
}

\section{Gerardo Soto, Miguel Núñez}

Universidad de Talca, Facultad de Ciencias Forestales. Talca, Chile.

Autor para correspondencia: gsoto@utalca.cl

Recibido: 31.10. 2007. Aceptado: 12.05. 2008.

\section{RESUMEN}

En el presente estudio, se utilizó carbonilla de carbón vegetal y aserrín de Pinus radiata (D. Don) para fabricar pellets, con similares características en peso, volumen y densidad, manteniendo como única variable, la cantidad de aserrín y carbonilla en cada pellets.

Utilizando una prensa de tornillo manual, se elaboró un total de 1180 pellets con 15 proporciones distintas de carbonilla y aserrín. Con estos pellets se realizaron ensayos de friabilidad y poder calorífico. Esta última propiedad se determinó utilizando un protocolo de medición y la Norma alemana DIN 51900.

Según los resultados, se concluye que es posible fabricar pellets de carbonilla, utilizando aserrín de Pinus radiata (D. Don) como material aglomerante, con un $50 \%$ de ambas materias primas, obteniendo la combinación óptima con un $47,5 \%$ de carbonilla y una friabilidad de 0,935 , logrando una ganancia energética de $24,25 \%$ con respecto a un pellet de $100 \%$ de aserrín.

Palabras claves: Pellets, pino radiata, friabilidad, poder calorífico superior.

\begin{abstract}
In the present study, it was used charcoal of vegetal coal and sawdust of Pinus radiata (D. Don) to manufacture pellets, these had similars characteristics by weight, volume and density, keeping as the only variable, the sawdust and charcoal quantity of each pellet.

Using a manual screw press, was manufactured a total of 1180 pellets with 15 different charcoal and sawdust proportions. With these pellets were conducted a friability and calorific power essays. This latter property was determined using a protocol for measuring and German Standard DIN 51900.

According to the results, was concluded that is possible manufacture pellets of charcoal, using sawdust of Pinus radiata (D. Don) as a adhesive material, with $50 \%$ of both raw materials, obtaining the optimum combination with a $47.5 \%$ of charcoal and a friability of 0.935 , achieving a gain energy of $24.25 \%$ compared to a $100 \%$ pellets of sawdust.
\end{abstract}

Keywords: Pellets, Pinus radiata, friability, superior calorific power. 


\section{INTRODUCCION}

El sector forestal chileno y su industria maderera, han tenido un gran crecimiento en los últimos años. Esto debido a la existencia de importantes recursos forestales de rápido crecimiento, alcanzando los 2 millones de hectáreas. Para el año 2004 la cantidad de madera producida sobrepasó los 32 millones de $\mathrm{m}^{3}$, como consecuencia, la generación de madera aserrada aumenta la cota de subproductos (aserrín) que alcanzan el 20\% del total de la troza (Lignum, 1977), llegando a la cifra no menor de 6,4 millones de $\mathrm{m}^{3}$ anuales. Estimaciones para el año 2011 indican que la disponibilidad de biomasa, como subproductos en Chile, alcanzarán los 18,4 millones de $\mathrm{m}^{3}$ y que para el 2021 será de 22,4 millones de $\mathrm{m}^{3}$, esto permite deducir que el $20 \%$ de la energía eléctrica, se podría producir utilizando biomasa como fuente de energía (Rodríguez 2006)

En la actualidad la utilización de los subproductos forestales tiene un alto grado de desaprovechamiento. El aserrín, viruta, despuntes, entre otros, se almacena en grandes cerros o se quema en calderas, sin poseer un mayor valor agregado o alcanzar una eficiencia energética mayor.

Una de las vías para utilizar los residuos madereros es convirtiéndolos en pellets o briquetas, conocidos también como biocombustibles sólidos densificados. Estos biocombustibles (pellets) tienen forma cilíndrica con diámetros normalmente comprendidos entre 7 y $22 \mathrm{~mm}$ y longitudes de 3,5 a 6,5 cm, cuya fabricación se realiza a alta presión, sin necesidad de utilizar algún tipo de adhesivo (Marcos y Núñez, 2006). Al fabricar y comercializar este tipo de combustibles, se disminuye considerablemente la cantidad de residuos, se reduce el volumen transportado, así como también se logra una combustión más limpia y eficiente.

La combustión de los pellets es más atractiva ambientalmente debido a que reduce las emanaciones de $\mathrm{CO}_{2}$ en un 50\% comparado con la combustión de leña o astillas, posee bajas concentraciones de azufre y nitrógeno entre $0.004-0.007 \%$ y $0.05-0.16 \%$ del peso seco final de cada pellet respectivamente (Rojas, 2004). La materia prima tiene un contenido de humedad entre 8 a $12 \%$, obteniendo una eficiencia energética de $4500 \mathrm{kcal} / \mathrm{kg}$ como poder calorífico superior (Ortiz et al. 2003). En consecuencia la combustión de pellets contribuye a disminuir las concentraciones de $\mathrm{CO}_{2}, \mathrm{SO}_{\mathrm{x}}$ y $\mathrm{NO}_{\mathrm{x}}$ causantes del "efecto invernadero" y el cambio climático.

El consumo de combustibles fósiles, petróleo y sus derivados, genera una dependencia en la vida cotidiana. Chile importa el 72\% de la energía que consume (en 2004: 98\% del crudo, 96\% del carbón y $75 \%$ del gas natural) (CNE, 2006). Esta dependencia esta enfocada mayoritariamente hacia el sector industrial, ya que necesitan del petróleo para sus procesos, pero preocupantemente los yacimientos de petróleo, según los más pesimistas, se agotarán en los próximos 25 a 30 años. Por esta y otras razones, se potencian las nuevas alternativas de energía, y entre éstas, los biocombustibles que deberían jugar un papel fundamental.

El carbón vegetal es un material poroso, frágil y con alto contenido de carbono (cercano al $80 \%$ de su peso), es producido por calentamiento de la madera en ausencia de aire $\left(400\right.$ a $\left.700{ }^{\circ} \mathrm{C}\right)$, con un poder calorífico superior entre 7090 y $7850 \mathrm{kcal} / \mathrm{kg}$ (Marcos, 1989). En la zona centro sur de Chile, la producción de carbón vegetal se masifica año tras año. El proceso de fabricación del carbón vegetal, su transporte y el movimiento del producto, genera abundante residuo o carbonilla. Este residuo se acumula en grandes cantidades al no poder reutilizarlo o quemarlo en su totalidad. Una buena manera de disminuir este tipo de residuos es reutilizándolo como un biocombustible mezclándolo con aserrín. Pacheco (1999), señala que es posible fabricar pellets mezclando $50 \%$ de carbón vegetal y $50 \%$ de aserrín, para obtener 5700 $\mathrm{kcal} / \mathrm{kg}$ aproximadamente. Sin embargo, solo se conoce que el carbón residual se mezcla con almidón líquido, para fabricar briquetas de uso doméstico (Alakangas, 2002). 
El objetivo de este estudio es determinar la combinación óptima entre aserrín y polvo de carbón, para la fabricación de pellets, utilizando diferentes proporciones de aserrín de Pinus radiata (D. Don) como material aglomerante, en donde se realizarán ensayos de resistencia al golpeteo (friabilidad) y de eficiencia energética (poder calorífico superior).

\section{METODOLOGIA}

Este estudio se realizó en los laboratorios del CERTIM (Centro Regional de Tecnología e Industria de la Madera) de la Universidad de Talca. Para esto fue necesario utilizar una prensa de tornillo manual (Figura 1), la cual permite fabricar pellets de $1,1 \mathrm{~cm}$ de diámetro y largos comprendidos entre los 1,5 y $2,0 \mathrm{~cm}$.
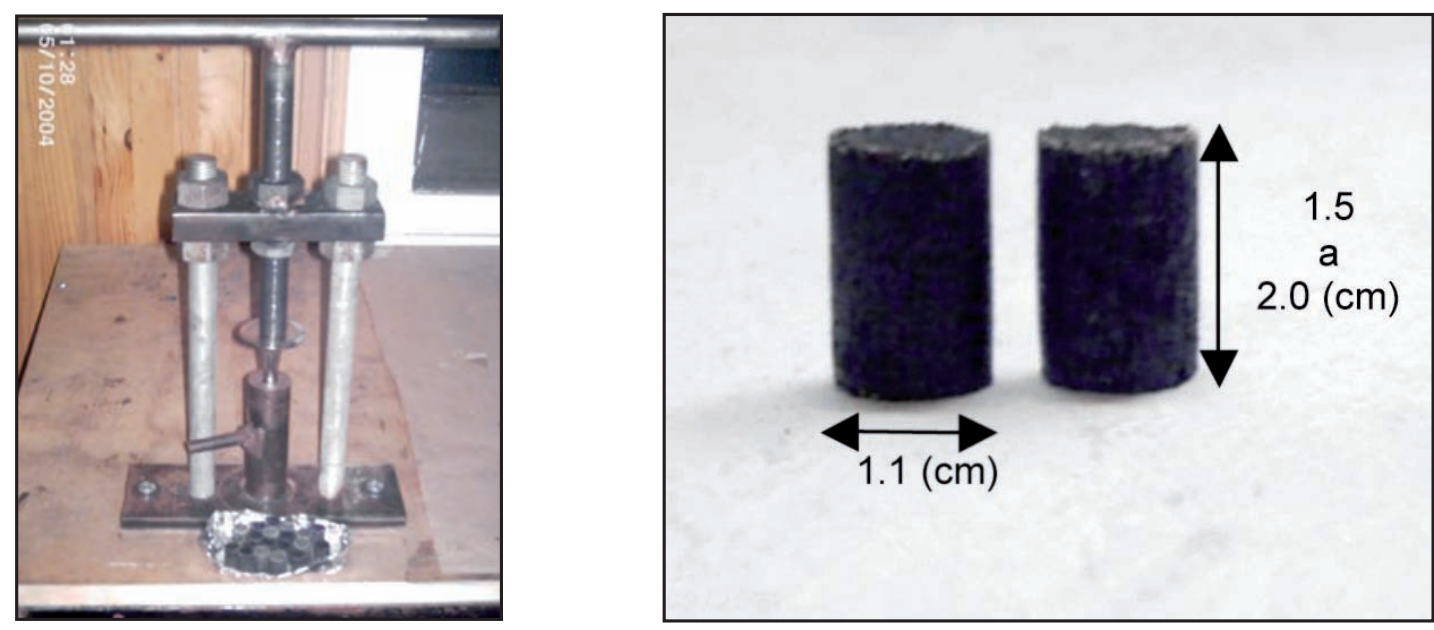

Figura 1: Prensa de tornillo manual para fabricar pellets.

El primer procedimiento fue calcular el contenido de humedad, para lo cual se tomaron 3 muestras de aserrín y carbonilla, donde luego se procedió a pesar $4 \mathrm{~g}$ de cada muestra. Estas se secaron en una estufa a $100 \pm 5^{\circ} \mathrm{C}$ por aproximadamente $24 \mathrm{hrs}$. Luego de dos a tres pesadas en donde se mantuviera el peso constante, se calculó el contenido de humedad por medio de la fórmula de diferencia de peso, la que arrojó un resultado promedio de 9,9\% para la mezcla de aserrín y carbonilla.

Siendo $\mathrm{CH}$ el contenido de humedad de las materias primas.

$$
C H=\frac{\mathrm{P} \text { inicial }-\mathrm{P} \operatorname{seco}}{\mathrm{P} \operatorname{seco}} * 100
$$

Conocido el contenido de humedad, se procedió a fabricar los patrones de referencia: pellets de carbonilla y de aserrín al $100 \%$. Los resultados demuestran que con 100\% de carbonilla no se logra pelletizar.

Las proporciones de carbonilla utilizadas en esta parte, estuvieron comprendidas entre el $90 \%$ y el 10 $\%$, complementadas con aserrín, en tramos o intervalos de 5 y $10 \%$. Como dato referencial, se fabricaron 100 unidades para cada proporción. 


\section{Ensayos de Friabilidad}

Los ensayos de friabilidad se realizaron simultáneamente cada vez que se terminaba de fabricar 100 pellets de cada proporción, usando el método comúnmente ocupado en los Laboratorios de Termodinámica y Motores de la Universidad Politécnica de Madrid (ETSI de Montes). Este ensayo consiste en arrojar uno a uno cada pellet de una altura de $1 \mathrm{~m}$, hacia un suelo cerámico y observar en cuantas partes se rompe cada uno (2, 3 o más partes). Después de ensayados una cantidad igual a 100 pellets, se calcula una proporción entre los pellets iniciales y los resultantes al final de cada ensayo. La fórmula utilizada para los cálculos de friabilidad se presenta a continuación:

$$
\mathrm{FR}=\frac{\mathrm{N}_{\mathrm{i}}}{\mathrm{N}_{\mathrm{f}}}
$$

Siendo FR la friabilidad resultante (adimensional), $\mathrm{N}_{\mathrm{i}}$ el número de pellets al inicio del ensayo y $\mathrm{N}_{\mathrm{f}}$ el número de pellets al final del ensayo (enteros y fraccionados) (Marcos y Camps, 2002).

\section{Ensayos de Poder Calorífico Superior}

Este ensayo se realizó en el laboratorio de Química y Recursos Naturales de la Universidad de Talca. Para el desarrollo de este ensayo fue necesaria la utilización de una Bomba Calorimétrica Parr Co (Figura 2), siguiente un protocolo de medicion y la norma alemana DIN 51900-1: 2000 (DIN 51900-1: 2000). Se seleccionaron 3 pellets de cada una de las proporciones más resistentes al golpeteo, según los ensayos previos de friabilidad. Las actividades se ejecutaron en dos etapas:

1. Calibración de la Bomba Calorimétrica Parr Co, utilizando pastillas de ácido benzoico.

2. Determinación del poder calorífico superior de los pellets, mediante la siguiente fórmula, puesto que la cantidad de Azufre y Nitrógeno están en bajas concentraciones:

$$
H_{X}=\frac{C_{\text {bomba }} * \Delta t-\left(Q_{z}\right)}{m_{\text {comb. }}}
$$

Siendo $\mathrm{H}_{\mathrm{x}}$ la potencia calorífica del combustible $(\mathrm{kcal} / \mathrm{kg}), \mathrm{C}_{\text {bomba }}$ la capacidad calorífica de la bomba $(\mathrm{kcal} / \mathrm{kg}), \Delta \mathrm{t}$ la variación de temperatura del agua $\left({ }^{\circ} \mathrm{C}\right), \mathrm{m}_{\text {comb. }}$ la masa del combustible $(\mathrm{g})$ y $\mathrm{Q}_{\mathrm{z}}$ el calor de oxidación del alambre fusible (kcal).

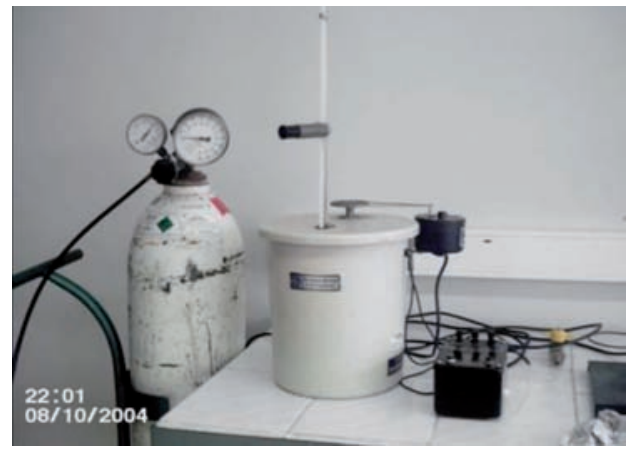

Figura 2: Bomba Calorimétrica Parr Co. 


\section{RESULTADOS Y DISCUSION}

La comprobación y el análisis de resultados se realizó utilizando el programa estadístico STATGRAPHICS Centurión XV2, usando los test de análisis de varianza ANOVA, el test de comparación de medias para la mínima diferencia significativa (LSD), el método de Student Newman Keuls, el chequeo de varianza y el test Kolmogorov Smirnov (K-S) todos con un 95\% de confianza.

\section{Friabilidad}

Como se puede apreciar en la figura 3, la friabilidad se mantuvo relativamente constante desde la proporción de $10 \%$ a $45 \%$ de carbonilla, además se incluyen los valores para $100 \%$ de aserrín $(\mathrm{FR}=1,00)$ y $100 \%$ de carbonilla $(\mathrm{FR}<0,20)$, estableciéndose así resultados máximos y mínimos de friabilidad, respectivamente. Se acepta como "buena" una resistencia al golpeteo (friabilidad) con un valor de 0,93 o superior. Esto indica que al arrojar 100 pellet al suelo cerámico se obtienen sólo 7 pellets rotos en 2 partes; obteniéndolo cuando el porcentaje de carbonilla es de 47,5\%. Con una proporción mayor la friabilidad disminuye considerablemente.

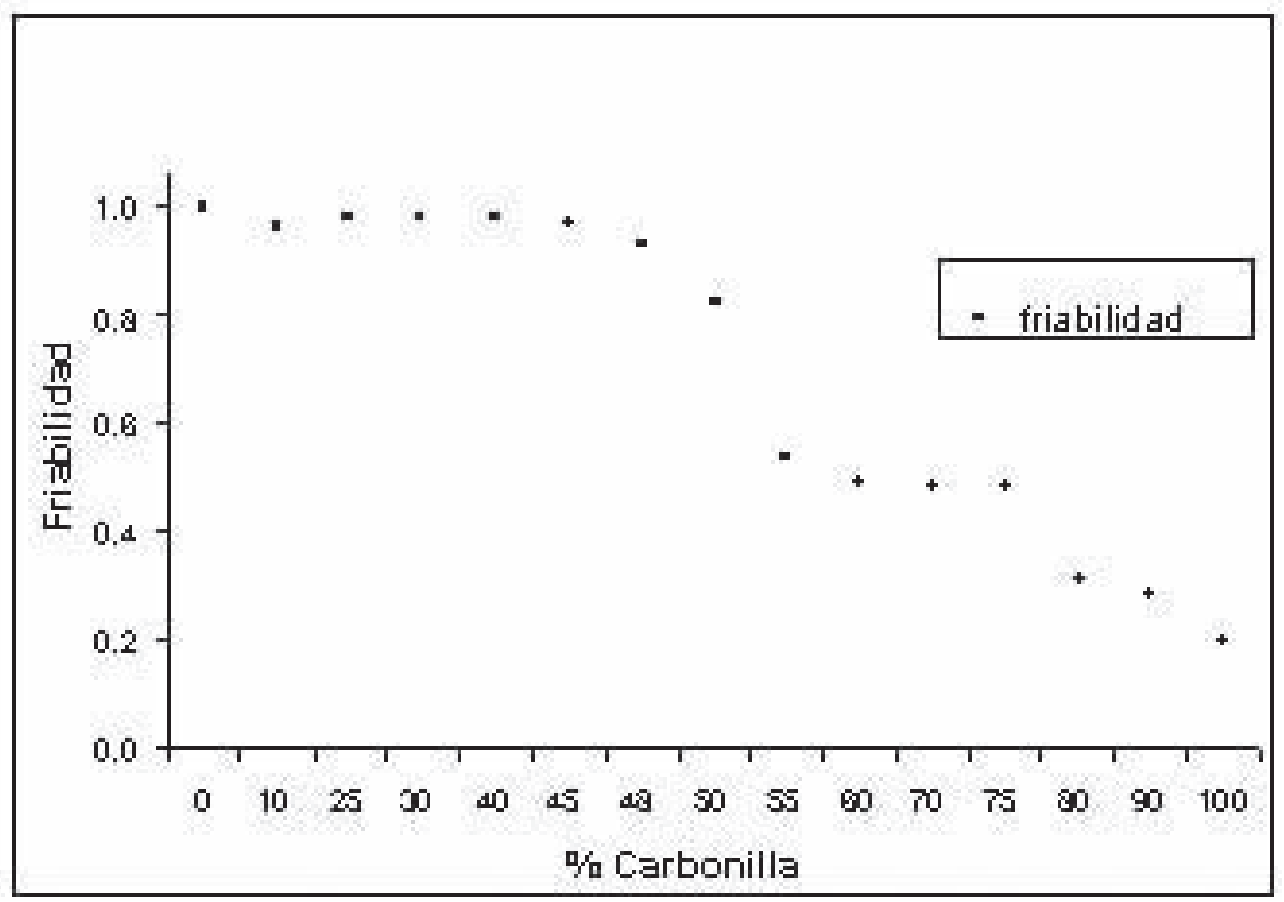

Figura 3. Comportamiento de la friabilidad 
La propiedad ligante o adhesiva del aserrín (por el entrelazamiento de las fibras), se manifestó desde el comienzo de la experimentación ( $90 \%$ carbonilla), demostrando que desde el $10 \%$ a $50 \%$ de carbonilla los pellets son significativamente más resistentes al golpeteo.

El análisis de varianza para la friabilidad (ANOVA), indica que existen diferencias estadísticamente significativas entre las medias. Mediante el chequeo de la varianza y el análisis de residuos, se determinó que la dispersión de los datos, sigue una distribución normal. El análisis estadístico de la friabilidad comprueba los supuestos de normalidad y homocedasticidad, aceptándose así la hipótesis nula, ya que a medida que aumenta la cantidad de carbonilla, disminuye la resistencia al golpeteo.

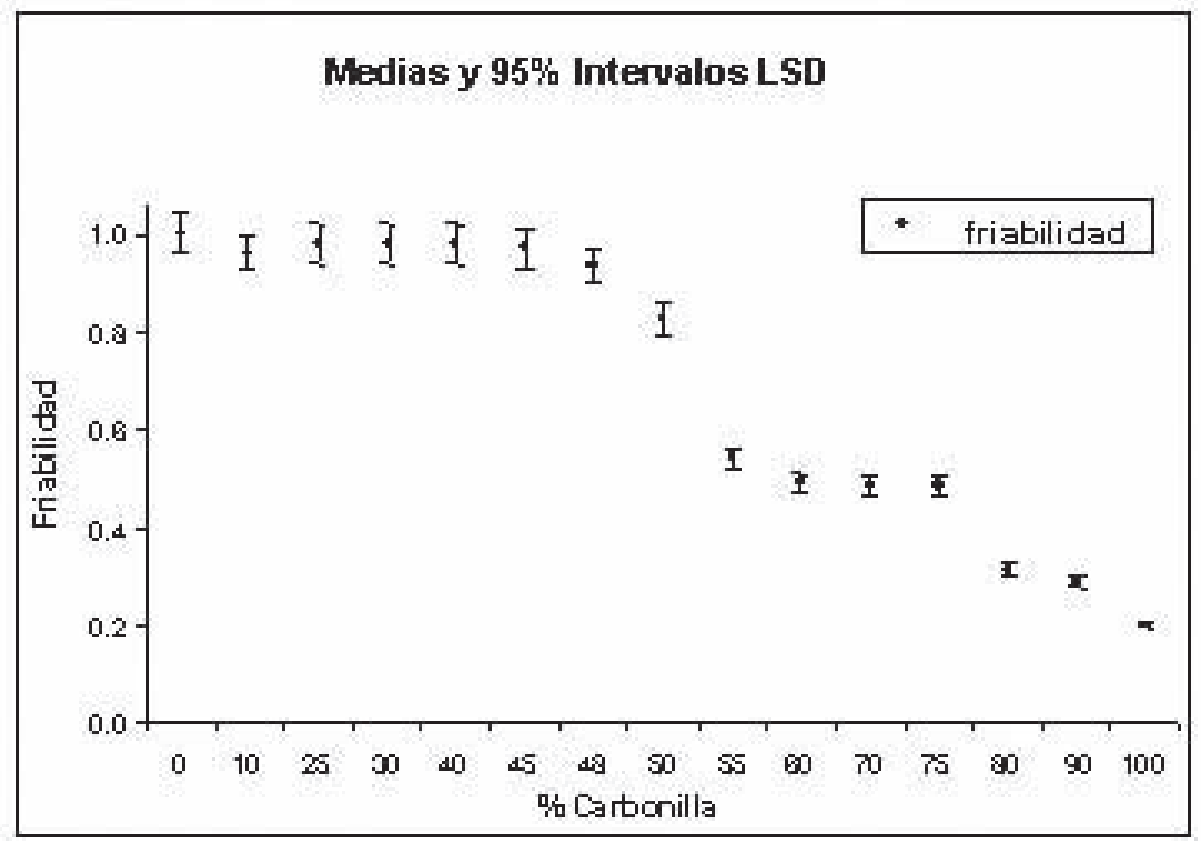

Figura 4. Distribución de los datos de friabilidad

En la Figura 4, según el test LSD (mínima diferencia significativa), la amplitud de los datos observados indica que la friabilidad para las proporciones desde el 10 al 47,5\% de carbonilla, es igual, estableciéndose una tolerancia de resistencia al golpeteo en esta última proporción (47,5\% de carbonilla). 


\section{Poder calorífico}

Al igual que con la friabilidad los resultados se analizaron con el programa estadístico STATGRAPICHS Centurión XV2, donde la hipótesis nula es que la cantidad de carbonilla en los pellets, ayuda a aumentar el poder calorífico.

En primera instancia se calibró la Bomba Calorimétrica Parr Co, obteniendo un resultado promedio para 4 pastillas de Ácido Benzoico de $2570.2 \mathrm{kcal} / \mathrm{kg}$. Este resultado es fundamental para calcular el poder calorífico superior de los pellets.

Las proporciones a utilizar según el ensayo previo de friabilidad son de: 50, 47.5, 45, 40, 30 y 25 \% de carbonilla, por ser las que presentaron mayor resistencia al golpeteo (friabilidad). También se consideró el análisis de poder calorífico en 4 pellets de aserrín puro, para tener un patrón de referencia. La tabla 1 considera los poderes caloríficos promedios obtenidos en el ensayo.

Tabla 1. Poderes Caloríficos promedios

\begin{tabular}{|c|c|}
\hline \multicolumn{2}{|c|}{ Poderes caloríficos promedio } \\
\hline \% Carbonilla & Poder calorífico (kcal/kg) \\
\hline 0 & 4098,6 \\
\hline 25 & 4057,3 \\
\hline 30 & 4233,2 \\
\hline 40 & 4417,9 \\
\hline 45 & 4900,3 \\
\hline 47.5 & 5092,4 \\
\hline 50 & 5381,2 \\
\hline
\end{tabular}

El valor máximo obtenido fue de $5381,2 \mathrm{kcal} / \mathrm{kg}$ para la proporción de $50 \%$ de carbonilla. Sin embargo, se considera óptima la proporción de $47,5 \%$ de carbonilla, puesto que es más resistente al golpeteo; en este punto se estableció un nivel de tolerancia para la friabilidad de los pellets, con la finalidad de obtener una combustión más eficiente. La gráfica de estos valores demuestra un crecimiento sustancial a medida que aumenta la cantidad de carbonilla en los pellets.

Según el análisis de ANOVA, existen diferencias significativas entre las medias, por lo que al chequear la varianza, se determina que no existen diferencias significativas para la desviación estándar. El análisis de los residuos permite concluir que la dispersión de los datos sigue una distribución normal. De igual forma permite comprobar los supuestos de normalidad y homocedastidad, aceptándose la hipótesis nula, donde a medida que aumenta la cantidad de carbonilla en los pellets, aumenta también el poder calorífico. 


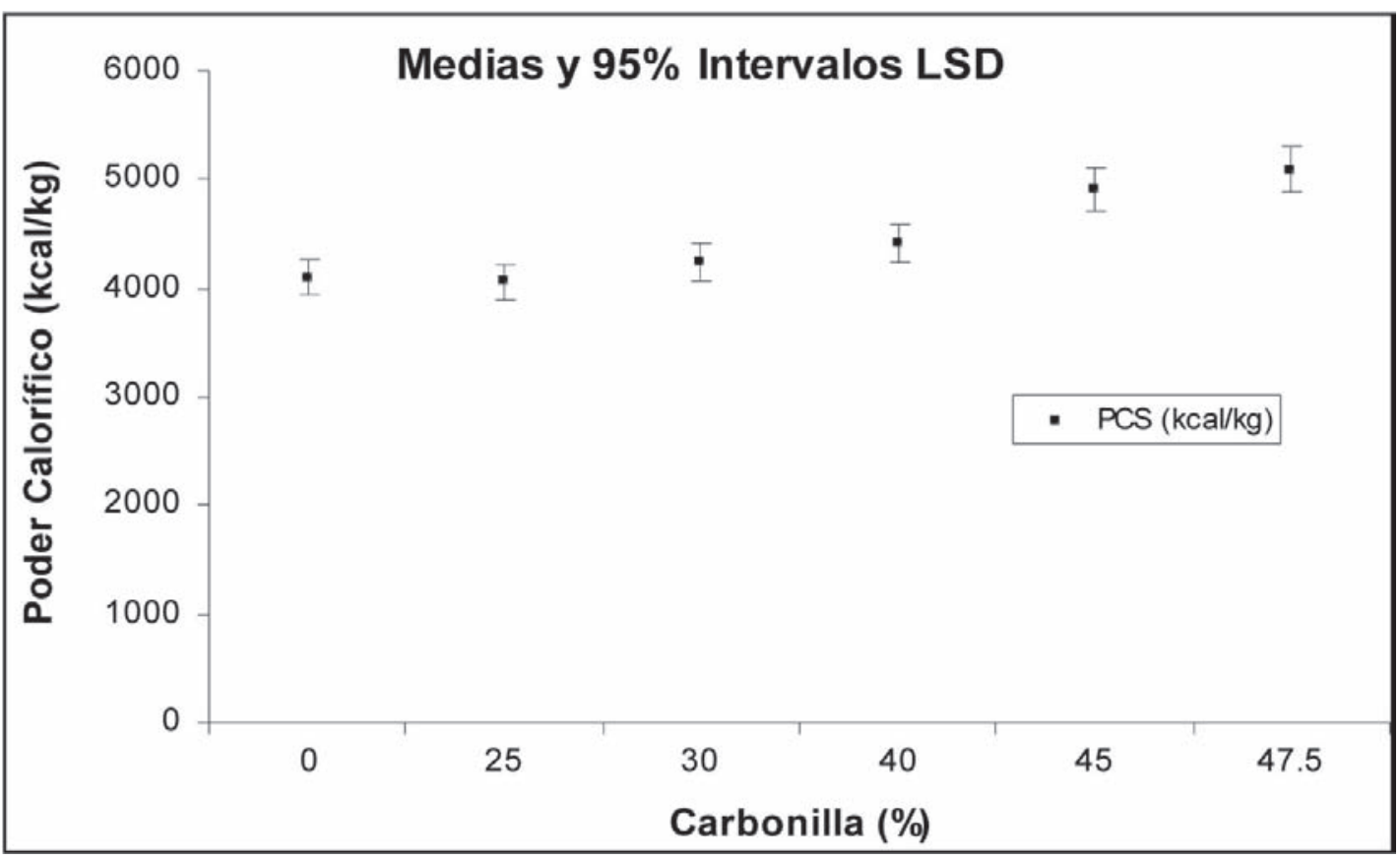

Figura 5. Distribución estadística de los datos para el Poder Calorífico.

En la Figura 5, se puede apreciar que por la amplitud de los datos, existen diferencias estadísticamente significativas. Se descarta el 50\% de carbonilla al estar fuera de la tolerancia de resistencia y se acepta como con valor máximo de poder calorífico superior la proporción de 47,5\% de carbonilla.

De los resultados obtenidos, se puede inferir que la mejor calidad de los pellets se encuentra entre las proporciones de 40 a $50 \%$ de carbonilla, con rangos de friabilidad comprendidos entre 0,98 a 0,83 y para el poder calorífico los valores obtenidos se encuentran entre 4417,9 a 5381,2 kcal $/ \mathrm{kg}$, respectivamente.

\section{CONCLUSIONES}

La propiedad de adhesión natural del aserrín incide directamente en la friabilidad, ya que al aumentar la proporción de esta materia prima los pellets se hacen más resistentes.

La densidad varió en el rango de 1 a 1,2 g/ $\mathrm{cm}^{3}$. Cuando la cantidad de carbonilla comienza a incrementarse, se observa que la densidad aumenta hasta un valor máximo de $1.19 \mathrm{~g} / \mathrm{cm}^{3}$ y luego comienza a disminuir. Esto se debe, a que la carbonilla ayuda a la compresibilidad del material hasta un punto máximo, pero luego el exceso de finos no permite pelletizar completamente todo el material.

Con un $47,5 \%$ de carbonilla y un 52,5\% de aserrín, la friabilidad alcanza un valor equivalente a 0,94 (7 pellets rotos de cada 100) y un poder calorífico superior de $5092,5 \mathrm{kcal} / \mathrm{kg}$, originando una ganancia energética de $24,25 \%$ con respecto al poder calorífico superior referencial de los pellets de aserrín $(4098,6 \mathrm{kcal} / \mathrm{kg})$.

La combinación óptima para fabricar este tipo de pellets, es de 47,5\% de carbonilla y 52,5\% de aserrín de Pinus radiata (D. Don), puesto que las características de friabilidad y poder calorífico son las más adecuadas para su manipulación y posterior uso como biocombustible. 


\section{AGRADECIMIENTOS}

Al Dr. Sergio Urzua del Laboratorio de Química y recursos naturales, por su disposición y colaboración en los ensayos de poder calorífico superior.

Al Dr. Oscar Vallejos de la Facultad de Ciencias Forestales, por su colaboración en el análisis estadístico de los datos.

\section{BIBLIOGRAFIA}

Alakangas, E. 2002. Wood pellets in Finland, technology economy and market. OPET Report 5, Technical Research Center of Finland (en línea). Jyväskylä, Finland. Disponible en http://www.tekes. fi/opet/pdf/OPET_report5_june2002.pdf

Rodríguez, M. 2006. La biomasa forestal como fuente de energía. Ambiente Forestal. 1 (2): 7p

CNE. 2006. Balance Nacional de Energía 2001 (en línea). Gobierno de Chile, Chile. Disponible en http://www.cne.cl

DIN. 2000. Pruebas en combustibles sólidos y líquidos. Determinación del poder calorífico superior mediante bomba calorimétrica y cálculo del poder calorífico inferior. Parte 1: principios, aparatos, métodos. DIN 51900-1.

Lignum. 1977. Ficha Forestal: Aserrín. Fundación Chile. Lignum (20) : 33-34

Marcos, F. 1989. El Carbón Vegetal propiedades y obtención. Madrid, España. Mundi-presa. 99 p.

Marcos, F.; Camps, M. 2002. Biocombustibles Sólidos Densificados. Madrid, España. Mundi-prensa. $154 \mathrm{p}$.

Marcos, F.; Núñez, M. 2006. Biomasa forestal: fuente energética. Energética XXI IV (52): 80-85.

Pacheco, A. 1999. Estudio Técnico-Económico de la fabricación de pellets de aserrín. Tesis Ing. Forestal. Talca, Chile. Universidad de Talca. Escuela de Ciencias Forestal. 10-56 p.

Rojas, M. 2004. Prefactibilidad Técnica y Económica para la instalación de una planta de pellets para combustibles a partir de desechos de madera. Tesis Ing. Forestal. Santiago, Chile. Universidad de Chile. Escuela de Ciencias Forestales. 22-26 p.

Ortiz, L.; Tejada, A.; Vázquez, A.; Piñeiro, G. 2003. Aprovechamiento de la Biomasa Forestal producida por la Cadena Monte-Industria. Parte III: Producción de elementos densificados (en línea). Galicia, España. Disponible en http://www.cismadera.com/downnloads/biomasaiii.php 
